\title{
Teología e historia: el marxismo trágico y esperanzado de Terry Eagleton
}

\section{Theology and history: the tragic and hopeful Marxism of Terry Eagleton}

ARTÍCULO

\author{
Sergio Blanco Gonzalia \\ Universidad Nacional de Jujuy, Argentina.
}

Recibido: agosto de 2021

Aceptado: octubre de 2021

\section{Resumen}

El propósito de este artículo es abordar el modo en que Terry Eagleton se distancia de toda teleología triunfalista proponiendo, en cambio, una perspectiva trágica de la historia, la cual, desde su perspectiva, no resulta impugnadora de la esperanza sino que es condición para ella. Así, Eagleton se sirve de nociones teológicas para sustentar su visión trágica de la historia, y de esa manera ofrecer una respuesta ante la ruina de la interpretación historicista y teleológica del devenir, la cual fue predominante en el marxismo del siglo XX.

Palabras clave: Terry Eagleton; Marxismo; Teología; Tragedia; Esperanza.

\begin{abstract}
The purpose of this article is to address the way in which Terry Eagleton distances himself from any triumphalist teleology by proposing, instead, a tragic perspective on history, which, from his perspective, is not an impugnation of hope but rather a condition for it. Thus, Eagleton uses theological notions to support his tragic vision of history, and thus offer an answer to the ruin of the historicist and teleological interpretation of becoming, which was predominant in 20th century Marxism.
\end{abstract}

Keywords: Terry Eagleton; Marxism; Theology; Tragedy; Hope.

\section{Introducción}

En función de exponer la perspectiva trágica y esperanzada de la historia asumida por Terry Eagleton, el artículo se organiza como sigue. En primer lugar (1) se ubicará la reflexión de Eagleton en el marco de la crisis teórica del marxismo, particularmente de la bancarrota de una mirada historicista teleológica de la historia que, aunque no era la única lectura posible del legado teórico de Marx, sí fue predominante en el siglo XX. El segundo paso (2) atenderá a las implicancias morales de la interpretación de la historia antedicha, es decir, a la posibilidad de una teodicea marxista, y al rechazo de Eagleton a una lectura de la historia en esa clave. El siguiente movimiento (3) desplegará la visión trágica de la historia sostenida por nuestro autor, quien entiende que la misma se puede encontrar tanto en la fe cristiana como en el marxismo. De dicha perspectiva se desprende la necesidad de la autonegación como condición para la posibilidad de la transformación integral requerida (dado que el 
mundo está inmerso en la catástrofe): es el tema que será tratado posteriormente (4), a partir de la noción de sacrificio. Cierra el artículo una argumentación acerca de la esperanza. Primeramente se la distinguirá del optimismo (5.1). Finalmente se abordará la esperanza en una perspectiva histórica, como esperanza de futuro (5.2).

\section{La crisis del marxismo como contexto: ruina de la teleología historicista}

Resulta ineludible iniciar nuestro desarrollo refiriendo al contexto de crisis en que se encuentra, desde hace ya algunas décadas, la tradición teórica y política a la que Eagleton adscribe: el marxismo. Un abordaje en profundidad de la crisis del marxismo escapa a los propósitos de este artículo, pero sí resulta fundamental presentar uno de sus ejes teóricos clave, en tanto marco intelectual en el que se inscribe (y que influye grandemente en) la reflexión de Eagleton en torno a la historia.

Si la crisis teórica del marxismo puede abordarse desde varios planos, es tal vez su concepción de la historia la que ha sufrido mayor menoscabo en las últimas décadas. Para comprender ésta, así como su quebranto, resultan sumamente valiosas las consideraciones de Gerald Cohen (2001) en torno a lo que él denomina la "concepción obstétrica de la práctica política". Según dicha concepción el socialismo (y luego el comunismo) aparece como consecuencia de la propia auto transformación del capitalismo, de manera endógena. Así, la solución al problema (el capitalismo) es proporcionada por la conclusión de su desarrollo, es decir, se presenta cuando el problema se encuentra completamente desarrollado. En La ideología alemana Marx y Engels dicen: "Para nosotros, el comunismo no es un estado que debe implantarse, un ideal al que haya de sujetarse la realidad. Nosotros llamamos comunismo al movimiento real que anula y supera al estado de cosas actual" (1974, p. 37). El comunismo es un movimiento real porque proviene de la misma realidad; reemplaza el estado actual de las cosas, lo supera, a partir de la conclusión de ese movimiento. De manera que para la concepción obstétrica de la política, indica Cohen (2001, p. 97), el socialismo no se construye "externamente", sino que se debe proceder como un obstetra, dado que el socialismo se encuentra inscrito en la dinámica existente. Por lo tanto, si el capitalismo está "embarazado" de socialismo se requiere de una "comadrona" para el alumbramiento. En otras palabras, el socialismo se encuentra en la dinámica de la historia, y la concurrencia de la voluntad humana (la acción política) posibilita asistir a dicho parto:

[P]iensen en el embarazo. La futura madre puede creer que tendrá a su bebé en una semana o mes concreto, pero eso no significa que no haya que hacerle sitio a una comadrona cunado llegue ese momento. Así, también, el capitalismo está embarazado con el socialismo, pero se necesita de la política adecuada para asegurar su alumbramiento seguro (Cohen, 2001, p. 64). 
De este modo, el socialismo se encuentra en la dinámica de la historia y la concurrencia de la voluntad humana, la acción política, posibilita asistir a dicho parto. Con mayor o menor énfasis en la solicitud a la "comadrona", la idea es la misma: el futuro, anhelado, deseado, es uno, y se encuentra inserto en la dinámica presente (la alternativa a que el porvenir se "caiga" es la "barbarie"); y hay que colaborar para alcanzar esta solución.Esta metáfora obstétrica se encuentra claramente expuesta en Contribución a la crítica de la economía política, donde Marx (2008) presenta de modo sistemático su teoría de la historia. Señala allí que al agotarse un orden social, al marchitarse lo que puede ofrecer a la humanidad a partir del incremento de su poder productivo, en forma sincronizada surge un nuevo orden para reemplazar al caduco, y este nuevo orden se encuentra dentro del pretérito.

Hoy esta concepción de la historia se encuentra devastada: se ha minado la certeza en las bondades del curso histórico y la confianza en la necesidad histórica del socialismo (Petruccelli, 2016, p. 21). Esta visión historicista y teleológica de la historia, "la presunción de que el porvenir nos depara un mundo de sabiduría total, certidumbre plena y abundancia ilimitada donde por ello seremos libres, justos, fraternos y felices" (Bartra, 2016, p. 70), se encuentra invalidada.

\section{Frente a la teodicea}

El debate en torno a la concepción de la historia en Marx y el marxismo, sobre su carácter "obstétrico"-historicista y teleológico (o no), se extiende inabarcablemente. No es objeto de nuestra investigación indagar tal cosa, sino el modo en que Eagleton concibe la cuestión; es decir, no abordaremos cuál(es) era(n) la(s) concepción(es) de la historia en Marx o en tal o cual corriente marxista, sino lo que dice Eagleton al respecto. En este sentido, lo primero que destaca es lo siguiente: "Lo de hasta dónde cree Marx en la necesidad histórica no es solo una cuestión política y económica: también tiene una relevancia moral" (Eagleton 2018a, p. 65). ¿Por qué indica esto nuestro autor? La palabra clave para responder a ello es "teodicea".

Como es sabido, el término "teodicea", compuesto a partir de los vocablos griegos theós (Dios) y díkê (justicia), fue acuñado por Gottfried Liebniz (2013), para referirse "a una nueva disciplina filosófica específicamente dedicada a la justificación de la omnipotencia, la sabiduría y la bondad divinas, frente a las objeciones fundadas en la presencia del mal en el mundo" (Echavarría, 2009, p. 1083).Teodicea, entonces, remite a una búsqueda de justificación de Dios, de explicar el mal eximiéndolo de responsabilidad.Si consideramos que, para Eagleton, la historia "hasta la fecha ha sido, en su mayor parte, un relato de sangre y despotismo" (2015, p. 187), en la cual "[l]os seres humanos han venido desollándose y masacrándose entre sí desde el principio de los tiempos" (2008, p. 14), el asunto es si todas estas abominaciones encuentran justificación. 
La teodicea, apunta Eagleton (2015, p. 160), tiene distintos argumentos para explicar el mal, tales como que el mal resulta esencial para construir el carácter moral, dándonos la oportunidad de hacer el bien, o que resulta un preludio necesario del bien. Esta última idea es concomitante a la idea de Progreso, que entiende la historia como un proceso que evoluciona orgánicamente, dando lugar sucesivamente a fases que superan a sus antecesoras. En pos de un futuro siempre mejor, garantizado por la marcha ineluctable de la historia, las atrocidades del presente aparecen justificadas, así como lo están las crueldades del pasado que nos han permitido llegar hasta las actuales alturas de la historia. Se trata, según Eagleton, de una teodicea secularizada para la cual "[l]a satisfacción del presente debe ofrecerse en nombre del futuro, y la historia es el margen de este infinito aplazamiento" (2008, p. 149). A quienes adoptan esta perspectiva de la historia, aunque la violencia y la explotación pueden resultarles deplorables, les parecen necesarias.

La cuestión (moralmente) relevante para nuestro autor es si la teoría de Marx (y del marxismo) propone una teodicea. Eagleton (2015) aborda el tópico frontalmente:

\begin{abstract}
¿Creen los marxistas que los males del capitalismo son también algo bueno, porque conducirán finalmente a una situación más deseable conocida como socialismo? Marx, desde luego, no escatimó elogios al capitalismo al considerarlo el modo de producción más revolucionario jamás visto en la historia. Es cierto, sí, que se trata de un sistema explotador que ha castigado a la humanidad con horrores indecibles. Pero, desde el punto de vista de Marx, también ha potenciado las capacidades de hombres y mujeres hasta límites sin precedentes [...] ¿Significa eso que la «Caída» de la historia en el capitalismo fue no sólo afortunada, sino también necesaria? ¿Podría haber un socialismo verdadero sin ella? ¿Acaso no resultó precisa la existencia del capitalismo para desarrollar la riqueza de la sociedad hasta el punto en que el socialismo pueda ya encargarse de ella y reorganizarla en interés de todos y todas? (pp. 164-165).
\end{abstract}

El párrafo anterior encierra al menos dos cuestiones en torno al capitalismo: su necesidad y su valoración. Respecto al primera tema, la postura en torno a la necesidad del capitalismo y de su máximo desarrollo como fase inevitable previa al socialismo fue defendida dentro del marxismo por una importante corriente de la II Internacional (que en Rusia estuvo representada por los mencheviques, y en gran parte del mundo Occidental mantendrá durante el siglo XX la denominación de "socialdemocracia"). Realizando una lectura férreamente etapista de la obra marxiana, asumirán la historia como una sucesión de modos de producción, donde el esclavismo, aunque terrible, habría sido necesario ya que condujo al feudalismo, y así sucesivamente. Eagleton nos dice que "esta ideología constituiría un ejemplo claro de teodicea, pues trataría de justificar unos males históricos insistiendo en el bien al que finalmente han dado lugar" (2015, p. 165).

Ahora bien, nuestro autor entiende que esta interpretación de la obra de Marx no es algo descabellado. Eagleton (2018a, pp. 49-51) sostiene que la teoría marxista presenta problemas, ya que parece indicar que para existir el socialismo es inevitable que antes haya un sistema capitalista que desarrolle las fuerzas productivas, y ello requiere de acumulación, 
lo que conlleva explotación y violencia. Las injusticias aparecerían como necesarias para la justicia futura (ya que de otro modo el socialismo no contaría con base material suficiente):

Esto plantea algún que otro espinoso problema moral. Del mismo modo que algunos cristianos aceptan el mal como algo necesario en cierto sentido dentro del plan de Dios para la humanidad, hay una posible lectura del marxismo que vendría a decir que, por muy avaricioso e injusto que sea el capitalismo, es un mal que conviene soportar por el bien del futuro socialista que aquel traerá inevitablemente tras su estela. $Y$, de hecho, no conviene solo soportarlo, sino incluso fomentarlo activamente (2018a, p. 66).

De esta interpretación se desprende una dudosa moralidad (incontables crímenes se han cometido en el nombre de un marxismo recubierto por teodiceas de este calibre), en el mejor caso de tipo consecuencialista, que Eagleton rechaza terminantemente. Si bien nuestro autor reconoce que hay en la teoría de Marx elementos que sirven de base a una interpretación de este tipo, opta por no tomar de modo literal los pasajes "obstétricos" presentes en los escritos marxianos: rechaza, por tanto, este historicismo teleológico, y, en consecuencia, queda sin base una teodicea en nombre del futuro.

Esto nos conduce a la segunda cuestión: la valoración del capitalismo. Eagleton (2018a), como fue mencionado, al rechazar una concepción historicista y teleológica de la historia no interpreta que haya por parte del marxismo una valoración positiva del capitalismo en función de un radiante futuro socialista:

El marxismo no sugiere que los crímenes del capitalismo estén justificados por el posterior advenimiento del socialismo, ni afirma que el capitalismo emerja por necesidad histórica. Los modos de producción no surgen necesariamente. No están ligados a todas las etapas previas por ninguna lógica interna. Ningún estadio del proceso existe por causa de los otros (p. 68).

Ciertamente, hoy día muy pocos marxistas defenderían que el capitalismo surge del feudalismo como una férrea necesidad, ni que el socialismo se sigue necesariamente del capitalismo. Como fue mencionado, en el marxismo ha quedado descreditada una concepción historicista y teleológica de la historia que de base a una teodicea en nombre del futuro. Ahora bien, Eagleton (2018a) indica que

hay una diferencia entre, por un lado, hacer el mal con la esperanza de obtener un bien y, por otro, tratar de dar un buen uso al mal de otros. Los socialistas no perpetraron el capitalismo y son inocentes de los crímenes de este. Pero dado que ya existe, parece racional intentar sacarle el máximo partido. Esto es posible porque, es evidente, el capitalismo no es simplemente malo sin más (p. 67).

En tanto el capitalismo existe, Eagleton (2015, p. 166) nos dice que los marxistas deben buscar el modo de poner al servicio de toda la humanidad los recursos materiales y 
espirituales gestados en este sistema. $\mathrm{Y}$ ello es así porque la valoración que Eagleton (2012a, p. 95) realiza del capitalismo se encuentra equidistante tanto de los entusiastas del Progreso como de los enemigos de la llustración (tanto en su versión conservadora como posmoderna). Si frente a los segundos subraya que el capitalismo ha gestado beneficios indudables, valiosos no meramente de cara al futuro, sino en sí mismos (por caso, la extensión del ciclo vital humano), a los primeros les recalca que "la barbarie y la civilización no son solo secuenciales: también son sincrónicas" (Eagleton, 2012a, p. 123). De acuerdo a su lectura, Marx habría visualizado el carácter ambivalente de la modernidad: por un lado habría destacado los méritos históricos de la burguesía, aunque por el otro habría alertado sobre los terribles costos humanos que el progreso conlleva. ${ }^{1}$ De modo que en la obra de Marx se revelaría el costado oscuro de la razón de los ilustrados, al subrayar la explotación y opresión sin la cual el progreso de la sociedad burguesa habría sido imposible, aunque ello no convertiría a Marx en un enemigo de la llustración (en términos de Callinicos -2011habría sido una de las grandes figuras de la "Ilustración radicalizada"). De hecho, nos dice Eagleton (2012a), solo el marxismo cuenta la historia de la llustración de manera que los dos relatos de ella, el que destaca sus logros y méritos, y el que señala su papel legitimador de una cultura capitalista que ha conducido a terribles actos de barbarie, son dos caras de la misma moneda:

La repuesta radical a la pregunta de si la modernidad es un fenómeno positivo o negativo es un sí y un no igualmente categóricos [...] ]ha sido al mismo tiempo un avance fascinante para la humanidad y una pesadilla insoportable, haciendo patente además que esta última parte de la historia es el reverso de la primera, de tal modo que ambas versiones fusionadas forman un todo estructuralmente solidario (o cómplice, más bien) y no una mera yuxtaposición contingente (pp. 94, 95).

En esta valoración de la modernidad y del capitalismo (y más en general de la historia) como una conjunción de logros y desdichas, ${ }^{2}$ de civilización y barbarie, ${ }^{3}$ Eagleton se inclina por enfatizar los segundo términos: "Visto en su conjunto, el de la historia humana ha sido más un relato de escasez, suplicio y explotación, que una fábula de urbanidad y progreso"

\footnotetext{
1"Marx estaría de acuerdo en que la modernidad ha constituido una alentadora historia de progreso, prosperidad y emancipación [...] No obstante [...] Marx no solo ve en ella una crónica de triunfos y horrores, sino que considera que estas dos narraciones están estrechamente entrelazadas. Según él, las mismas fuerzas que posibilitan la libertad y la riqueza también malogran potencialidades humanas, generan desigualdad y pobreza, y ejercen un dominio despótico sobre las vidas humanas. No puede haber civilización sin barbarie, catedrales o grandes empresas sin explotación y miedo a la miseria" (Eagleton, 2016, pp. 35, 36).

2 Acerca del capitalismo: "El capitalismo ha creado más prosperidad de la que nunca antes había contemplado la historia, pero el costo (por ejemplo, en términos de indigencia de miles de millones de personas) ha sido astronómico" (Eagleton 2018a, p. 21). Más en general, acerca de la historia: "La historia trae consigo algunos logros magníficos, sin duda, pero a costa de una dosis colosal de desdicha. Los marxistas son quienes creen que estos dos aspectos del relato de la humanidad se hallan estrechamente relacionados" (Eagleton 2015, p. 163).

3"Para el pensamiento radical, la barbarie continúa siendo una de las condiciones que posibilitan en secreto eso tan preciado que llamamos civilización" (Eagleton 2012a, p. 123).
} 
(2017a, p. 93). Su pensamiento al respecto, insuflado marcadamente por la obra de Walter Benjamin (de hecho, Eagleton dedica un profundo estudio -2012d-al pensamiento de éste), particularmente por las Tesis sobre la historia (2008), identifica la catástrofe como el continuum de la historia.

Mas el realce de unos u otros aspectos, positivos o negativos, la justipreciación (ya de por sí suficientemente negativa) que realiza del capitalismo (y de la historia) no modifican la idea base en Eagleton, que es que ningún logro (pasado o futuro) puede justificar el sufrimiento de millones y millones de seres humanos a lo largo del tiempo:

Desde un punto de vista marxista, el problema de si los frutos de la civilización justifican la barbarie que intervino en su formación queda abierta. Un marxista podría sostener (aunque sorpresivamente pocos de ellos lo hacen) que ninguna abundancia de futuras riquezas puede justificar el duro esfuerzo que ha sido el destino de la mayoría durante el transcurso de la historia de clases [...] Si hay una luz al final del túnel, ¿qué ocurre con aquellos que perecieron a lo largo de las vías y se perdieron al costado del camino, aquellos que no han tenido ninguna redención política, cuyos nombres han sido borrados de los registros históricos? (2017b, p. 149).

Profundizando en esta reflexión, en una tónica decididamente schopenhaueriana, Eagleton nos dice que tal vez hubiera sido preferible que la historia no tuviera lugar, que sería mejor si nada de esto hubiera sucedido, que "muchísimos hombres y mujeres nacidos en este planeta habrían estado casi sin lugar a dudas mejor si jamás hubieran llegado a ver la luz del día (2015, p. 187). La historia es un gran (y monótono) relato de violencia y explotación que ha azotado a la abrumadora mayoría de las mujeres y los hombres a lo largo de los siglos (2018a, p. 114); la barbarie lo ha recorrido todo y no deja de hacerlo. $\mathrm{E}$ incluso ninguna redención futura podrá justificar cabalmente el sufrimiento de nuestros antepasados:

Aunque seamos capaces de construir una sociedad justa, es posible que ésta no constituya recompensa suficiente para la atroz naturaleza de nuestro pasado y nuestro presente [...] no es irrazonable afirmar que, con socialismo o sin él, habría sido mejor que [la historia] nunca hubiera llegado a tener lugar(Eagleton,2015, p. 166).

De este modo, nos aproximamos al núcleo de la concepción trágica, en tanto, tal como señala el especialista George Steiner (2012), la tragedia conlleva implícitamente la idea de que lo mejor es no haber nacido, implica "una visión de la realidad en que se asume que el hombre es un huésped inoportuno en el mundo" (p. 12). En el siguiente apartado desplegaremos la comprensión de lo trágico que ofrece Eagleton.

\section{Sentido trágico de la historia (en el centro un cuerpo lacerado)}

"En el centro de mi religión", dijo Connolly, "hay un cuerpo lacerado. Está allí para escandalizar a los idealistas de este mundo: los que se consuelan 
pensando que las sociedades humanas no son tan malas como parecen" (Eagleton, 2017c, p. 162).

La visión de la historia que sostiene Eagleton podría parecer derrotista, sin embargo no es así. Él la denomina "trágica" y entiende que de ninguna manera se contrapone a la esperanza, sino que resulta esencial para ella (veremos esto hacia el final del artículo). ${ }^{4}$ Lo primero que debemos decir de la visión trágica de la historia que propone nuestro autor, es que la misma confronta directamente con el optimismo cándido del progresismo liberal. El humanismo trágico que Eagleton propugna, "comparte con el liberal el ideal del libre florecimiento de la humanidad, pero mantiene que esto sólo es posible si se afronta lo peor" (2012a, p. 201). La tragedia, entonces, parte de mirar al horror a la cara, afrontar el espanto, asumiendo que "sólo descendiendo a los infiernos, enfrentándose a lo que la humanidad tiene de salvaje, irracional y obsceno, es concebible la redención" (Eagleton, 2015, p. 88)

Nuestro autor entiende que esta visión trágica de las cosas no es ajena al marxismo. ${ }^{5}$ Si bien el relato marxista no tiene un final infeliz, afirma que no es un requisito de lo trágico el acabar mal. El sentido en que Eagleton (2018a, pp. 69, 70) cree que la visión del mundo que propone el marxismo es trágica es que, aun si la historia concluyera en un final feliz, es trágico que millones de seres humanos a lo largo de los tiempos hayan tenido que soportar tantas atrocidades ('La resurrección no cancela la realidad de la crucifixión, ni el comunismo

\footnotetext{
${ }^{4}$ Para otros especialistas, la visión trágica resulta incompatible con la esperanza. Así, para George Steiner (2012), la tragedia no puede incluir la expectativa en una resolución positiva o compensación, inmanente o trascendente. La tragedia es una visión estrictamente negativa y desesperanzada de la presencia del hombre en el mundo. Por su parte, para Lucien Goldmann (1986) la consciencia trágica no renuncia a la esperanza, pero no la sitúa en el mundo, siendo las esperanzas mundanas incompatibles con el pensamiento trágico. Según esta visión, la esperanza humana carece de toda perspectiva en el tiempo y en el espacio, no pueden depositarse en el mundo fenoménico auténticas esperanzas de realización del bien y la verdad, ya que la verdad y la justicia auténticas tienen un carácter trascendente que las opone al mundo, por ello el hombre trágico vivirá solamente para la eternidad.

${ }^{5}$ Aquí también la lectura de Eagleton se diferencia de las interpretaciones realizadas por George Steiner y Lucien Goldmann. Para el primero, el marxismo, al igual que el cristianismo, es anti-trágico. En el cristianismo, señala, hay garantía de certeza final, de reposo en Dios. Respecto al marxismo, Steiner indica que es un credo enormemente optimista: "Como el visionario medieval con su fe absoluta en el advenimiento del Reino de Dios, el comunista está seguro que el reino de la justicia está cerca. La concepción marxista de la historia es una Comedia secular. La humanidad marcha hacia la justicia, la igualdad y la comodidad de la sociedad sin clases [...] Claro que en el camino se presentan catástrofes. La burguesía condenada lucha por su vida con feroz astucia y, momentáneamente, puede lograr éxitos políticos o militares [...] También puede haber desviaciones heréticas y cismas dentro del bando socialista. Pero ni siquiera el más sombrío revés justificaría una desesperación trágica. La marcha sigue adelante, pues se basa en las leyes inexorables de la historia; la victoria final es tan segura como la llegada de la aurora" (pp. 267, 268).

Por su parte, Goldmann (1986) entiende que la consciencia trágica resulta superada por el marxismo. Para él, el marxismo conserva las principales exigencias del pensamiento trágico (carácter paradójico y contradictorio de la realidad humana y esperanza en la realización de valores que de sentido a la contradicción), pero sustituye la esperanza trascendente, por una esperanza depositada en el porvenir histórico y la comunidad humana. Así, el marxismo integra y supera a la consciencia trágica: acepta e integra los problemas planteados por el pensamiento trágico, pero le opone a la apuesta trágica sobre la eternidad y la existencia de una divinidad trascendente, la apuesta inmanente sobre el porvenir histórico y humano. En otro términos, Goldmann entiende que la consciencia trágica hace de la síntesis una exigencia tan absoluta como irrealizable (y ello es lo que hace que la condición del hombre sea trágica), mientras que para el marxismo la síntesis se sitúa en el terreno de lo posible, que el hombre puede realizar con su acción.
} 
los horrores de la sociedad de clases"-Eagleton, 2016, p. 65-). Según Eagleton, el sentido trágico de la historia asume que cualquier futuro distinto tiene como base el espanto de la historia, que la única posibilidad de redención parte de enfrentar el salvajismo y obscenidad que presenta la humanidad.

Nuestro autor señala que esta visión trágica de la historia también se encuentra firmemente asentada en la fe cristiana ortodoxa, tradicional y conforme a las Escrituras. En una perspectiva comparada, Eagleton afirma que la fe cristiana (y junto con ella la visión trágica de la historia que el marxismo -en su opinión- comparte) a diferencia del humanismo liberal, "[a]sume la depravación y la perversidad humanas en su plena y justa medida [...] Pero, al mismo tiempo, es mucho más atrevida que los humanistas y los racionalistas liberales en cuanto a que la posibilidad de tan funesta condición sea subsanable" (2012a, p. 69). ${ }^{6}$ Así, esta mirada sombría de la especie humana que es a la vez condición para una fe esperanzada, es compartida por la fe cristiana y por el marxismo. Es una visión que rechaza el fácil optimismo al tiempo que no se deja asir por las garras de la desazón, una perspectiva que Eagleton (2012a) denomina "realista":

Es en virtud de ese realismo imposible y fríamente desencantado, que mira fijamente a los ojos de esa Realidad monstruosa (con su cabeza de Medusa), traumática y obscena de la crucifixión humana, que quizá sea posible algún tipo de resurrección. Sólo aceptando esto como última palabra y verdad definitiva ( $\mathrm{y}$, por lo tanto, considerando todo lo demás como pura basura sentimentalista, ilusión ideológica, utopía ficticia, consuelo falso e idealismo ridículamente optimista), sólo entonces, digo, podría no ser la última palabra después de todo (p. 47).

Rememorando sus años infantiles como portero de un convento de clausura de monjas carmelitas, Eagleton (2004) encuentra que aquellas monjas portaban esta visión realistatrágica de la historia:

reconocían, a su manera un tanto retorcida, la vileza de la historia de la humanidad, a la cual habrían calificado sin dudar como el pecado del mundo, y eran así la cara opuesta de los entusiastas modernizadores del liberalismo [...] las monjas se aferraban a la opinión curiosamente pasada de moda de que en el mundo había demasiada violencia y crueldad como para considerarlas meramente accidentales o solucionables con reformas graduales [...] Para ellas, la imperfección de este mundo era tan profunda que exigía de una intervención radical, llamada redención en su jerga (p. 24).

La cita anterior deja asentado la afinidad que nuestro autor encuentra entre su propia visión (marxista y trágica) de la historia y la que tenían aquellas monjas en la cercanía de las cuales él aprendiera los fundamentos de la fe cristiana. Del reconocimiento del carácter

\footnotetext{
${ }^{6}$ Otra formulación de la misma idea: "Tanto los marxistas como los cristianos son más sombríos sobre la condición presente de la humanidad que los liberales y los reformistas sociales, aunque tienen mucha más confianza sobre sus perspectivas futuras [...] Se tiene fe en el futuro precisamente porque se intenta encarar el presente con sus aspectos más abominables [...] es una visión trágica" (Eagleton, 2016, p. 23).
} 
atroz de la historia humana, se desprende la siguiente noción: la profunda crueldad de la historia humana no es subsanable si no media una intervención radical. De modo que hay un "diagnóstico" común (la catástrofe como continuum de la historia o el pecado del mundo) y hay también un segundo punto de conjunción entre el marxismo y la fe cristiana, y que responde a una visión trágica del mundo: el tratamiento debe ser radical. Eagleton entiende que tanto el marxismo como la fe cristiana reconocen que no es posible enmendar la situación actual con reformas parciales, sino que se requiere una transformación integral: "Lo que está en juego no es un proyecto reformista consistente en llenar de vino nuevo odres viejos, sino un inimaginable régimen nuevo" (Eagleton, 2012b, p. 23). ${ }^{7} \mathrm{Y}$ esta segunda característica se liga a un tercer aspecto, la autorrenuncia: "El humanismo trágico, en cualquiera de sus versiones (socialista, cristiana o psicoanalítica), sostiene que sólo mediante un proceso de autorrenuncia y de reconstrucción radical podrá la humanidad realizar su verdadero potencial" (Eagleton, 2012a, p. 202). Veremos estos dos últimos aspectos a continuación, introduciendo la forma en que Eagleton concibe el sacrificio.

\section{El sacrificio como signo de reconstrucción radical}

Eagleton aborda el tema del sacrificio (literalmente "convertir en sagrado"), centrando su reflexión en el significado del mismo para la fe cristiana. Presenta la cuestión indicando que para que un pedazo de vida humilde se convierta en algo especial y poderoso debe sufrir un proceso de muerte y disolución: "El sacrificio incumbe el paso de la humillación al poder de ese objeto vilipendiado" (Eagleton, 2008, p. 150). La clave, entonces, retomando el parágrafo anterior, es puntualizar que la reconstrucción radical requiere de la autonegación.

Eagleton (2018b, p. 12) advierte que el escepticismo de la modernidad hacia el sacrificio es producto de su comprensión incierta de dicha noción, asimilada sencillamente a la renuncia voluntaria; empero la renuncia es solo una cara del sacrificio, y no siempre la más prominente. Para nuestro autor "[l]a versión más convincente del sacrificio se refiere al florecimiento del yo, no a su extinción" (Eagleton, 2018b, p. 14) ${ }^{8}$. Es un proceso que implica la transformación del sujeto humano, un tránsito de la muerte a la nueva vida. El sacrificio, ciertamente, involucra la pérdida, pero en nombre del florecimiento pleno de la vida, ceder algo para poseerlo más plenamente. El sacrificio, señala Eagleton (2018b, p. 15), anuncia el paso de la debilidad al poder, de la condición de víctima a la humanidad completa, y del mundo existente a su transfiguración.

\footnotetext{
${ }^{7}$ Referencia a la parábola del vino nuevo en odres viejos, mencionada en: Mateo 9:14-17, Marcos 2:21-22 y Lucas 5:33-39.

${ }^{8}$ En el original: "The most compelling version of sacrifice concerns the flourishing of the self, not its extinction" (Eagleton, 2018b, p. 14).
} 
De modo que para Eagleton (2008, p. 151) el sacrificio tiene la estructura interna de la tragedia, ya que la creación se produce mediante la pérdida, así como también el sacrificio es trágico en el sentido de que es lamentable que se muestre como algo necesario. En una sociedad justa no habría lugar para el sacrificio, para tal autodisolución radical; es el hecho de que existe una situación nefasta lo que torna necesario "una kenosis tan extrema" (Eagleton, 2008, p. 151). Es debido a "la urgencia y gravedad de nuestra situación -a lo que los Evangelios se refieren como el «pecado del mundo»-, [que] el logro de un orden social justo implica pasar por la muerte, la nada, la turbulencia y el autodesposeimiento" (Eagleton, 2012b, p. 24).

$\mathrm{Si}$ las virtudes sacrificiales tienen su lugar, es porque la justicia y el bienestar no son posibles sin ellas. Es precisamente este el sentido que para Eagleton tenía el sacrificio de las hermanas carmelitas que lo impresionaron en su infancia: el papel de aquellas consistía en "simbolizar la drástica entrega que sería necesaria para que el mundo se convirtiera en un lugar justo. Ellas no ofrecían indicaciones sobre lo que habría que hacer, sino de cuánto esfuerzo iba a costar" (Eagleton, 2004, p. 26). Que tal entrega sea necesaria es un asunto trágico, no una oportunidad enviada por el cielo para demostrar coraje moral (Eagleton, 2018b, p. 35).

Es en esta perspectiva que Eagleton interpreta a Jesús como un protagonista trágico:

Es curioso que el Nuevo Testamento no presente el sufrimiento de Jesús como heroico. No hay nada intrínsecamente glorioso en su muerte [...] Para la cultura judeocristiana que originó los Evangelios, el sufrimiento es inequívocamente malo. Ha de ser soportado más que glorificado. Jesús nunca aconseja a los enfermos que se reconcilien con su aflicción [...] Si podemos arrancar algo positivo a nuestra angustia, tanto mejor; pero aún será mejor si no nos es necesario (2010, pp. 506,507).

El sufrimiento y la muerte de Jesús no son presentados por los Evangelios como un acto heroico; el sufrimiento es siempre algo malo. Es así que Eagleton (2018b, p. 68) entiende el episodio de Getsemaní (Mateo 26: 36-38), como una escena interpolada por los escritores del Evangelio para demostrar, entre otras cosas, que Jesús no desea morir:

La fe cristiana resulta ser el trágico acto de enfrentarse con la pena y la desesperación con el fin de redimirlas; pero esto solo es posible si se las ve tal cual son, no como envidiables oportunidades de ejercitar los músculos morales. El Jesús del Nuevo Testamento nunca les aconseja a los enfermos reconciliarse con su sufrimiento. Por el contrario, parece considerar el origen de sus dolencias como un mal. En Getsemaní, presa del pánico ante la perspectiva de su propia muerte inminente, ora para ser liberado de su destino (Eagleton, 2017b, p. 150). ${ }^{9}$

${ }^{9} \mathrm{Al}$ respecto, Eagleton señala que en el Evangelio de Juan se encuentra un enfoque distinto: "El contraste entre las últimas palabras de Jesús en el Evangelio de Juan «Consumado es», y la de, por ejemplo, el Evangelio de Marcos, «Dios mío, Dios mío, ¿por qué me has abandonado?», es sorprendente. El Jesús de Juan parece por encima del dolor y los improperios a él dirigidos en las otras versiones. Juan omite cualquier escena de temor y desolación en Jesús. Su escena de la crucifixión parece saturada del triunfo de la resurrección, que el autor proyecta retrospectivamente sobre la cruz" (2012b, pp. 243, 244). 
El sacrificio, asume Eagleton (2018b, p. 70), no es entonces imagen de la buena vida, sino de lo que se necesita para lograrla. Ningún tipo de sacrificio (desde el martirologio al ascetismo, la prohibición, la autorrepresión), constituyen modos de vida en sí mismos. Son malas formas de vida, empero son al mismo tiempo (y desgraciadamente) un medio esencial para el logro práctico de la virtud y la justicia, así como "un medio para dar testimonio de su perdurable posibilidad mediante un rechazo estratégico de los consuelos del presente" (Eagleton, 2010, p. 122). La catastrófica situación en que existimos demanda la suspensión de la "buena vida", lo cual es un hecho trágico pero ineludible.

Nuestro autor entiende que esta valoración del sacrificio es común al cristianismo y al marxismo. Para ambas perspectivas, señala, el sacrificio no es una forma de vida recomendable, empero resulta necesaria. De este modo, Eagleton señala que para Marx el sacrificio es una forma de vida

trágicamente necesaria si ha de obtenerse una buena vida para todos. No sucedería así si la historia no fuera tan funestamente opresiva como es. Infeliz es la tierra que necesita de mártires, y también la que necesita de radicales. Dado que la historia ha sido tan atroz, su transformación inevitablemente significará que algunas personas deban sacrificar al menos parte de su propia realización por el bien de los demás [...] El revolucionario autodisciplinado y que se sacrifica es, entonces, la última persona que puede brindarnos una imagen de un futuro emancipado. Ese revolucionario no es un signo de ese futuro, sino de cuanto se necesita para lograrlo [...] De modo parecido, el monje o el religioso célibe no es la imagen del Paraíso, sino sólo un dramático significante de cuánto, en un mundo injusto, deberá sacrificarse para lograrlo (2012c, p. 145).

Esta interpretación del sacrificio, común al marxismo y a la fe cristiana, contrasta con la actitud liberal moderna, la cual, como fue mencionado, se limita a visualizarlo como autonegación. ${ }^{10}$ Ello es así, señala Eagleton, porque el liberalismo moderno no ve que la historia humana es catástrofe (véase el apartado anterior), tienen una mirada indulgente del hombre. $Y$ no asume, por tanto, que no hay espacio para el gradualismo, sino que lo que se requiere es una ruptura radical (de ese continuum catastrófico), que la situación no puede regenerarse sin un quiebre fundamental: "[El sacrificio] le planta cara a la ilusión consoladora de que se puede lograr la realización sin una ruptura y renacimiento fundamentales" (Eagleton, 2018b, p. 15). ${ }^{11} \mathrm{Y}$ finalmente, el liberalismo moderno no alcanza a ver que, precisamente, el sacrificio es el preludio para la creación (y no simple autonegación), la

\footnotetext{
10 Por su parte, "[l]a posmodernidad se muestra igualmente escéptica ante el sacrificio, en gran medida porque no está segura de que exista, en primera instancia, suficiente yo al que se pueda renunciar" (Eagleton, 2008, p. 150).

${ }^{11}$ En el original: "It sets its face against the consoling illusion that fulfilment can be achieved without a fundamental rupture and rebirth" (Eagleton, 2018b, p. 15).
} 
anuncia y es su requisito vital previo, es el signo y el agente de la emancipación humana (Eagleton, 2018b, p. 46).

Ahora bien, lo anterior no implica que el sacrificio conlleve garantía de éxito alguno. Anuncia lo nuevo, pero no asegura su realización, y por ello implica un acto supremo de fe. Más aún, Eagleton subraya que la cruz debe ser vivida en trágica resignación como final y absoluta, que la muerte no puede ser vista como un trampolín a la eternidad: "si Jesús hubiera considerado su hora en el Calvario simplemente como un pasaje a la gloria eterna, no habría sido levantado de entre los muertos. Solo viviendo la muerte de uno al máximo se puede convertir de un callejón sin salida a un horizonte" (Eagleton, 2018b, p. 68). ${ }^{12}$ De este modo, Eagleton sostiene que el reconocimiento de la pérdida es la fuente más fructífera de creación, que solo en la asunción del fracaso puede surgir la nueva esperanza. Tal es su lectura del Calvario:

Sólo si Jesús admitía que su misión no había llegado a nada, que era un miserable fracaso abandonado por sus compañeros aterrados, y sin embargo mantenía, contra esa confesión, su amorosa fidelidad a lo que consideraba la fuente de su ser, sólo así su muerte podía engendrar fruto en la vida de los otros(Eagleton, 2010, p. 506).

Indagaremos en el tópico de la esperanza en el siguiente apartado.

\section{Esperanza}

\subsection{Demarcación frente al optimismo progresista}

Lo único que entiende la clase dominante es la victoria. Pero subestima el poder del fracaso (Eagleton, 2017c, p. 123).

Si la esperanza es un tema que en los escritos de Eagleton aparece recurrentemente, aunque de forma dispersa, afortunadamente el autor hizo del tópico objeto de estudio particular en una obra reciente (publicada en 2015 y traducida al castellano en 2016): Hope Without Optimism. Dicho estudio inicia con la siguiente cita del teólogo dominico Herbert McCabe: "No somos optimistas; no presentamos una visión agradable del mundo con la que todos puedan entusiasmarse. Allá donde nos encontremos no tenemos más que una tarea concreta, estar del lado de la justicia, con los pobres" (Eagleton, 2016, p. 9). Asimismo, su primer capítulo lleva por título "La banalidad del optimismo". Huelga decir que la reflexión de Eagleton en torno a la esperanza se construye a partir del combate a la noción de optimismo.

Eagleton, entonces, distingue la esperanza del optimismo en tanto entiende que este último se vincula más bien a un rasgo del temperamento que recae en el fatalismo: inevitablemente las cosas tienden a salir bien. El optimista cree que aunque el presente no

\footnotetext{
12 En el original: "if Jesus had regarded his hour on Calvary simply as a passage to eternal glory, he would not have been raised from the dead. Only by living one's death to the full can it be converted from a cul-desac to a horizon" (Eagleton, 2018b, p. 68).
} 
sea el mejor de los mundos posibles ( $y$ en ello se diferencia del optimalismo al modo de Gottfried Liebniz) es mejor que el pasado, por lo que el futuro superará lo existente. Se desprende, desde luego, que no se requiere ninguna ruptura radical, sino dar continuidad al curso ascendente de las cosas. La mejor representación del optimismo en la filosofía de la historia la constituye la idea de Progreso.

Eagleton (2016, p. 50) considera que el optimismo progresista no es ajeno al marxismo; cantidad de escritos de reconocidos marxistas de diversas corrientes están inficionados por estas ínfulas (aunque desde luego ello no incluye a todos, y veremos a continuación la manera en que Eagleton combate la simbiosis entre marxismo y optimismo progresista). A modo de ejemplo, valgan estas palabras de un reconocido marxista hispanomexicano acerca de qué nos depara el devenir histórico: "Hay un progreso hacia una moral verdaderamente universal y humanista, que arranca de las morales primitivas y que pasa por las morales de clase con sus limitaciones y particularismos [...] cabe hablar de progreso, de elevación a niveles morales más altos" (Sánchez Vázquez, 1987, p. 215). En este sentido, Eagleton (2016, p. 51) cita la obra Literatura y revolución, del revolucionario bolchevique León Trotsky, destacando su desenfrenado entusiasmo acerca de las bondades del porvenir. ${ }^{13}$

Preciso es sacar a colación, en este punto, un debate ampliamente difundido en la reflexión filosófica acerca de la historia, que inicia a partir del postulado acerca de las raíces bíblicas que tendría la idea de Progreso. Este es el núcleo central del "teorema de la secularización", el cual sostiene que "la filosofía moderna de la historia arraiga en la fe bíblica en la consumación y termina con la secularización de su paradigma escatológico" (Löwith, 2007, p. 14). Desde esta perspectiva las construcciones modernas progresistas constituyen secularizaciones de la historia de salvación cristiana, suprimiendo las distinciones entre el reino trascendente de Dios y el mundo inmanente de los hombres. En base a una misma

\footnotetext{
${ }^{13}$ Eagleton refiere al siguiente pasaje del escrito de Trotsky: "El hombre libre tratará de alcanzar un equilibrio mejor en el funcionamiento de sus órganos y un desarrollo más armonioso de sus tejidos; con objeto de reducir el miedo a la muerte a los límites de una reacción racional del organismo ante el peligro. En efecto, no hay duda de que la falta de armonía anatómica y fisiológica, la extremada desproporción en el desarrollo de sus órganos o el empleo de sus tejidos dan a su instinto vital este temor mórbido, histérico, de la muerte, temor que a su vez alimenta las humillantes y estúpidas fantasías sobre el más allá. El hombre se esforzará por dirigir sus propios sentimientos, de elevar sus instintos a la altura del consciente y de hacerlos transparentes, de dirigir su voluntad en las tinieblas del inconsciente. Por eso, se alzará al nivel más alto y creará un tipo biológico y social superior, un superhombre si queréis. Igual de difícil es predecir cuáles serán los límites del dominio de sí susceptible de ser alcanzado, como de prever hasta dónde podrá desarrollarse la maestría técnica del hombre sobre la naturaleza. El espíritu de construcción social y la autoeducación psicológica se convertirán en aspectos gemelos de un solo proceso. Todas las artes -la literatura, el teatro, la pintura, la escultura, la música y la arquitectura- darán a este proceso una forma sublime. O más exactamente, la forma que revestirá el proceso de edificación cultural y de autoeducación del hombre comunista desarrollará hasta el grado más alto los elementos vivos del arte contemporáneo. El hombre se hará incomparablemente más fuerte, más sabio y más sutil. Su cuerpo será más armonioso, sus movimientos más rítmicos, su voz más melodioso. Las formas de su existencia adquirirán una cualidad dinámicamente dramática. El hombre medio alcanzará la talla de un Aristóteles, de un Goethe, de un Marx. Y por encima de estas alturas, nuevas cimas se elevarán" (Trotsky, 2014, p. 211).
} 
concepción de la historia como dirigida hacia un único final, meramente se transforma la esperanza bíblica en la salvación en la esperanza en un mejoramiento indefinido. De modo que, según esta perspectiva, la visión secular del progreso constituye una creencia dimanada de la fe cristina en un fin visualizado en el futuro; un éschaton que, en lugar de supramundano y definido pasa a ser intramundano e indefinido.

Este teorema de la secularización fue objeto de cuestionamientos, destacándose la crítica desarrollada por Hans Blumenberg (2008). Éste no ignora ni niega las similitudes estructurales entre la motivación teológica de una futura redención y la moderna noción de progreso, pero entiende que la filosofía moderna de la historia no está teológicamente afectada en su sustancia, sino solo en sus problemas:

La continuidad de la historia, traspasando el umbral de las distintas épocas, no radicaría en la supervivencia de las mismas substancias ideales, sino en esa hipoteca de los problemas que impone, una y otra vez, la obligación de saber lo que alguna vez antes ya se había sabido (Blumenberg, 2008, p. 56).

La tesis de Blumenberg, entonces, afirma que la validez de la categoría de secularización no es de tipo sustancial, sino meramente funcional: ambas (la filosofía de la historia y la historia cristiana de la salvación) otorgan posibles respuestas a la pregunta acerca del sentido de los acontecimientos históricos. La diferencia de sustancia de la escatología cristiana respecto a la idea de Progreso se advierte en que mientras la primera implica la irrupción en la historia de un acontecimiento heterogéneo a ella y que la trasciende, la idea de progreso opera a partir de la extrapolación de estructuras presentes hacia un futuro inmanente en la historia. De modo que en la escatología cristiana el acontecimiento escatológico irrumpe en la historia, mientras que la idea de Progreso no requiere de algo heterogéneo a la historia, sino que es su mismo desarrollo inmanente el que encierra el futuro. Por tanto, la primera requiere una discontinuidad, mientras que la segunda va alcanzando su meta a través de un tiempo continuo. Además, Blumemberg (2008, pp. 57-59) señala que mientras la idea moderna de progreso está teñida por la expectativa de un final feliz al cual cabe aproximarse sucesivamente, en la escatología cristiana la idea de un futuro cada vez mejor resulta ajena: la idea de progreso implica una concepción optimista del curso de la historia y de las capacidades del hombre, mientras que la escatología cristiana rechaza esa mirada cándida. ${ }^{14}$

Esta diferencia de "sustancia" entre la escatología cristiana y la idea de Progreso es advertida por Eagleton:

No es que la historia en su conjunto se esté aproximando al Todopoderoso, ascendiendo de altura en altura hasta su gloriosa consumación. Para el Nuevo

${ }^{14}$ Una mención por parte de Eagleton acerca de los aportes de Blumenberg se encuentra en: Eagleton, 2017b, p. 25. 
Testamento, el escatón o futuro reino de Dios no ha de confundirse con [...] la conclusión triunfal de un camino de progreso constante, sino como un acontecimiento que irrumpe de forma violenta e impredecible en la narración humana, trastornando su lógica, desafiando sus prioridades y desenmascarando su sabiduría como necedad. EI Mesías no emite la última nota de la melodía de la historia, sino que la interrumpe abruptamente (2016, p. 52).

¿Afirma entonces Eagleton que el Reino de Dios según la fe cristiana católica es algo completamente exógeno que irrumpe en la historia (al igual que lo plantea Blumenberg)? La cita anterior parece escorarse en ese sentido, mas luego el autor establece que para la fe cristiana el Reino de Dios se concibe dualmente, trascendente pero al mismo tiempo inmanente a la historia humana: "Si actúa de forma sigilosa en el presente, como la levadura en la masa, también se acerca subrepticiamente a hombres y mujeres como un ladrón en la noche" (Eagleton, 2016, p. 66). Si fuese absolutamente inmanente, no habría nada que enmendar en la humanidad, mas si fuera completamente trascendente, entonces no habría lugar para tener esperanza en ella (en términos cristianos, la naturaleza humana no sería receptiva a la gracia divina). En un lenguaje político secular, el inmanentismo nos conduciría a aquel historicismo (sea en su variante progresista liberal o marxista evolucionista) que, siguiendo a Walter Benjamin, Eagleton rechaza. Pero la perspectiva opuesta (trascendentalista) nos llevaría a adoptar una perspectiva apocalíptica según la cual "el suceso transformador irrumpe de forma impredecible en una historia degenerada en la que no hay casi nada valioso y no encuentra en ella ninguna base" (Eagleton, 2016, p. 66). ${ }^{15} \mathrm{Si}$ la primera perspectiva peca de optimismo, la segunda corre el riesgo de caer en un escepticismo desesperanzado. Eagleton (2016) indica:

Para una corriente más ortodoxa del marxismo, lo mismo que para la tradición católica del cristianismo, en el presente ha de vislumbrarse débilmente un futuro válido. De acuerdo con el marxismo, este se halla en fuerzas que aunque hayan sido generadas por el sistema actual son capaces de desbloquear sus contradicciones. Para que haya una esperanza genuina, el futuro debe estar anclado en el presente. No puede irrumpir en él desde algún espacio exterior metafísico. Al mismo tiempo, los poderes que actúan como la levadura en el presente lo hacen de una forma que al final sobrepasa sus límites, apuntando a una condición que está más allá de lo que podamos imaginar actualmente (p. 67). ${ }^{16}$

\footnotetext{
${ }^{15}$ Excedería al propósito de este escrito establecer la recepción y la crítica que Eagleton realiza de la obra de Walter Benjamin, en particular acerca de su concepción de la historia. Nótese, solamente, que Eagleton no comparte la noción que se desprende de ciertos pasajes benjaminianos acerca del suceso transformador como absolutamente trascendente: "Para el materialista histórico la propuesta final de esta tesis [Tesis B de Tesis sobre la historia de Walter Benjamin: "cada segundo era el estrecho postigo por el que podía entrar el Mesías"] es simplemente falsa. No todos los momentos son el estrecho postigo por el cual puede entrar el Mesías; la revolución socialista sólo ocurre bajo unas determinadas condiciones materiales en particular, no como un regalo trascendental o por medio de un voluntarioso aprovechamiento del tiempo. No hay manera de poner en armonía los aspectos apocalípticos de la imaginación histórica de Benjamin con su marxismo" (Eagleton, 2012d, p. 129).

${ }^{16}$ Una formulación distinta de lo mismo: "Un futuro verdaderamente diferente no sería ni una mera prolongación del presente ni una ruptura absoluta con este. Si fuera una ruptura absoluta, ¿cómo íbamos a reconocerlo? Pero, por otra parte, si pudiéramos describirlo bastante bien con los términos del presente,
} 
Eagleton (2016, p. 53) infiere que entre historia y escatología hay cierta continuidad, pero no en forma de bella teleología sino a partir de que diversos acontecimientos desperdigados en la historia pueden tornarse, el Día del Juicio, inteligibles en tanto proyecto redentor. Esta constelación de momentos diseminados aunque relacionados es lo que Benjamin llama "tradición", y de lo que se trata es encontrar las afinidades en esa historia secreta. De esta manera,

la escatología cristiana está muy alejada de la noción de una evolución sin límites. El Reino de Dios no se presenta como la nota culminante y triunfal de la melodía ascendente de la historia. Es la consumación, no de una majestuosa evolución histórica, sino de todos aquellos puntos álgidos en los que, a lo largo de la historia, los hombres y las mujeres han luchado por la justicia y, con ello, han ido prefigurando el advenimiento de la paz y la justicia universales, que en eso consiste el Reino de Dios [...] Como ya reconociera Walter Benjamin, el Reino de Dios no es más que el conjunto de esas luchas dispersas (a menudo condenadas de antemano al fracaso) libradas en nombre de los oprimidos sólo que vistas desde la perspectiva de la eternidad, reunidas en un nunc stans (o punto singular) donde se concentran para ser materializadas y redimidas en forma de relato coherente (Eagleton, 2012a, pp. 119, 120).

Mientras que para el progresista el pasado está completamente cerrado, muerto, y el futuro (siempre mejor que el presente) se encuentra abierto, Eagleton (2016, p. 58) sostiene (retomando los aportes de Benjamin) que es el pasado el que está abierto, el que es fluido, y su sentido está por determinarse: somos nosotros los que, desde el presente, podemos informarlo, a través de una lectura, pero sobretodo de nuestras acciones. De manera que nuestra responsabilidad recae no solo sobre el futuro, sino también sobre el pasado. La perspectiva de la esperanza trágica es que las luchas del pasado, la inacabable hilera de muertos que nos han antecedido con sus sufrimientos y combates, y que han sido derrotados, tal vez puedan redimirse si los evocamos en las luchas actuales: "Es imposible levantar a los muertos. Solo podemos darles otro significado con nuestras acciones en el presente. Es una especie de redención" (Eagleton, 2017c, p. 162). Así, el presente y el futuro "se alimentan de los recursos del pasado, entendiendo como tales una serie de tradiciones políticas valiosas que hay que luchar por mantener vivas" (Eagleton, 2018a, pp. 76, 77). Otra vez: se trata de aquella perspectiva trágica que busca obtener valor del fracaso, la pérdida, el sufrimiento y el dolor.

\subsection{Acerca de la esperanza}

¿en qué sería auténticamente distinto? La idea que Marx tiene de la emancipación rechaza tanto las continuidades sin sobresaltos como las rupturas totales" (Eagleton, 2018a, pp. 82, 83). 
En el segundo capítulo de Hope Without Optimism, Eagleton (2016, pp. 69-140) aborda de lleno el asunto de la esperanza. Parte de distinguirla del mero deseo, en tanto debe dirigirse a lo posible, al menos a lo considerado posible por quien espera. Por ello, a diferencia del deseo, la esperanza debe basarse en razones, aunque requiere menos justificación que la convicción (en términos de Lucien Goldmann -1986-, se trata de una "certeza incierta"). De modo que si la imposibilidad de algo no anula el deseo, si anula la esperanza, ya que ésta tiene que implicar lo posible, aunque no requiere de certezas:

No se puede esperar lo imposible, pero, según santo Tomás, lo que mejor ejemplifica esta virtud tampoco es lo que está a mano y es accesible sin más. Su objeto, escribe, es un bien que se encuentra en el futuro y que es difícil de obtener pero no inalcanzable (Eagleton, 2016, p. 85). ${ }^{17}$

La cita anterior enfatiza que la esperanza se orienta hacia un futuro que existe en el presente como posibilidad; la potencialidad articula presente y futuro. ${ }^{18}$ En este sentido, la esperanza se diferencia del deseo en tanto establece un vínculo entre un impulso presente y su consumación futura, combina la expresión de una carencia con la expectativa: "Es un movimiento hacia el bien, no simplemente un deseo de él. La esperanza se origina en el deseo, pero le añade un cierto empuje o entusiasmo, que no se da con el deseo corriente" (Eagleton, 2016, pp. 88,89).

Como también se desprende de la cita precedente, Eagleton (2016, pp. 95,96) piensa la esperanza como una virtud, es decir, como una disposición y no como una experiencia; pertenece a una forma de vida y no es un suceso aislado. Por lo que la esperanza no es una sensación, sino algo que se manifiesta en la actuación, en una práctica. Practicar la virtud de la esperanza es algo mucho más meritorio que ser optimista, dado que no cuenta con certeza de alcanzar su propósito: "La esperanza difiere del optimismo en que no anticipa confiadamente un resultado positivo" (Eagleton, 2010, p. 505). De modo que nuestro autor entiende la esperanza como un modo de deseo que incluye la expectativa, que se orienta hacia lo posible mas no cuenta con certeza de alcanzar su propósito, que encuentra sustento razones (aunque no convicciones), y que conlleva un impulso de realización, en tanto virtud que se manifiesta prácticamente.

Todo lo anterior referido a la esperanza no la torna de por sí en algo benigno (se puede tener esperanza en algo moralmente reprobable). Esperanza es un término engañosamente

\footnotetext{
${ }^{17}$ Eagleton (2016, p. 125) advierte que esperanza y conocimiento parecerían ser mutuamente excluyentes, pero matiza tal idea ya que, por ejemplo, el socialismo científico del siglo XIX tenía certeza en el advenimiento del socialismo y asimismo tenía esperanza. Del mismo modo, el cristianismo mantiene la esperanza algo sobre lo que tiene la convicción que ocurrirá.

${ }^{18}$ En este sentido la orientación hacia el futuro es algo compartido por la modernidad y la escatología cristiana: "La escatología, que implica «la primacía ontológica del futuro respecto al presente», es nada menos que la categoría central del judeocristianismo [...] Sin duda, esta predilección por el futuro no es un rasgo invariable del pensamiento moderno" (Eagleton, 2016, pp. 91, 92).
} 
afirmativo, empero "santo Tomás nos recuerda que hay aspiraciones falsas o dañinas" (Eagleton, 2016, p. 99). Sin embargo, en tanto virtud, la esperanza se puede cultivar, orientar, dirigir hacia lo moralmente bueno. $Y$ para ello debe intervenir la razón (si la racionalidad instrumental interviene buscando la manera de hacer realidad la esperanza, la racionalidad valorativa contribuye a designar sus fines). $Y$ sin embargo cierto contenido indeterminado es consustancial a la esperanza:

San Pablo dice que la esperanza «penetra más allá del velo», lo que significa que lo que tratamos de alcanzar está oculto [...] El objeto de la esperanza de san Pablo quizá sea elusivo, pero al menos él le puede dar el nombre de Dios. En todo caso, de sus palabras se desprende que los cristianos nunca pueden definir exactamente qué es lo que esperan. Por extraño que resulte, la esperanza misma es cierta [...] pero su objeto es oscuro [...] En la Epístola a los Hebreos se dice que, por la fe, Abraham obedeció al ser llamado «sin saber adónde iba», combinando lo determinado con lo impreciso a la manera de san Pablo" (Eagleton, 2016, p. 107).

De modo que es propio de la esperanza cierta indeterminación en lo que se propone realizar así como la ausencia de certezas en cuanto a su realización. Estos dos aspectos se hallan interrelacionados. Si lo último liga la esperanza a aquella visión trágica que insiste en "mirar la posibilidad del fracaso directamente a la cara" (Eagleton, 2010, p. 505), y que subsiste en medio de la debacle, como inclinación innata del ser, lo segundo indica que la esperanza es una inclinación que se orienta hacia algo que no puede definirse con precisión. Aquí nuestro autor retoma los desarrollos de Gabriel Marcel en torno a la "esperanza fundamental": "es posible dar una situación concreta por perdida, al tiempo que se conserva una confianza indeterminada en el futuro, que es a lo que Marcel se refiere con esperanza fundamental. Esa esperanza no tiene un objetivo concreto; más bien se trata de una apertura general del espíritu" (Eagleton, 2016, p. 116).

La esperanza fundamental es una especie de metaesperanza, la condición de posibilidad de todas nuestras aspiraciones más palpables: "Acaso no consista más que en el deseo de perseverar, no por algo en concreto, sino porque esa perseverancia es la precondición de llegar a querer o lograr algo concreto" (Eagleton, 2016, p. 117). Para Eagleton la esperanza es, en este sentido (limitado), performativa, ya que tener confianza en un futuro puede ayudarnos a realizarlo (del mismo modo, comportarse como si no hubiera esperanza puede inducir a que no la haya). La esperanza, además de anticipadora del futuro es una fuerza constitutiva del mismo, lo cual no quiere decir que la esperanza se realizará por el solo hecho de que encarne en nosotros (lo cual sería una recaer en un voluntarismo burdamente optimista):

Aun así, el mero acto de ser capaz de imaginar un futuro alternativo puede distanciar y relativizar el presente, reduciendo su poder sobre nosotros hasta el punto en que el 
futuro en cuestión se hace más viable [...] La verdadera desesperanza sería la imposibilidad de concebir estas visiones (Eagleton, 2016, pp. 134, 135).

De modo que la esperanza tiene un carácter dual: como proyecto y como crítica de lo existente. Es una búsqueda de superar la realidad de lo ya devenido, una incitación de la imaginación hacia un todavía-no (Bloch, 2007), que en su mismo acto puede corroer lo existente, que es aquello que se antepone al porvenir. Si aquello que todavía-no ha llegado a ser no puede definirse cabalmente, si, como afirma Eagleton, es propio de la esperanza cierta indeterminación, también, como fue señalado más arriba, la razón puede orientar la esperanza hacia lo moralmente bueno, que en el marxismo se identifica con la comunidad ideal, el comunismo.

\section{Conclusiones}

El artículo se apertura (1. "La crisis del marxismo como contexto: ruina de la teleología historicista") con una exposición de la crisis teórica del marxismo en lo que respecta a la concepción de la historia predominante en dicha tradición. Se explica el asunto retomando la crítica de Gerald Cohen a lo que él denominó "concepción obstétrica", esto es, la convicción de que el socialismo está inscrito en el movimiento real de las cosas, y por tanto es inevitable; se concluye indicando que este historicismo cándido hoy se encuentra plenamente invalidado.

En base a lo anterior, el apartado siguiente (2. "Frente a la teodicea") aborda un problema moral derivado de aquella concepción historicista teleológica: la cuestión de si el marxismo propone o no una teodicea. Es decir, si, al modo de un historicismo como el de la idea de Progreso, el mal aparece como un preludio necesario del bien, lo que justifica las atrocidades del pasado y del presente en nombre del futuro (con una lógica imbuida de esta idea, la socialdemocracia marxista entendía la "Caída" en el capitalismo como un mal necesario para el futuro socialista). Eagleton sostiene que en la obra de Marx pueden hallarse argumentos que den lugar a una interpretación de este tipo (al establecer como precondición para el socialismo el logro de un alto desarrollo de las fuerzas productivas, lo cual conlleva violencia y explotación, etc.), interpretación que da lugar a una dudosa moralidad. Sin embargo, nuestro autor entiende que el marxismo no sostiene una perspectiva historicista-teleológica que de base a una teodicea. Eagleton destaca (entendiendo que en ello sigue a Marx) el carácter ambivalente de la modernidad capitalista, lo cual se generaliza en una valoración de la historia como logros y desdichas, civilización y barbarie. Empero lo que predomina en su mirada son los últimos términos: el peso de las atrocidades inclina cualquier báscula. $Y$ en definitiva, Eagleton afirma que más allá de cualquier balance, ningún logro del pasado, ni tampoco el más brillante socialismo futuro, podrá justificar el sufrimiento de millones de seres humanos a lo largo de los siglos. 
Se prosigue (3. Sentido trágico de la historia -en el centro un cuerpo lacerado-) desplegando la visión trágica de la historia que sostiene Eagleton: ella parte de afrontar el carácter atroz de la historia, entendiendo que solo así podrá haber redención. Esta mirada, nos dice, no es ajena al marxismo (ya que el supuesto happy end no quita lo trágico que es el sufrimiento de millones a lo largo de la historia). Y asimismo, afirma nuestro autor, la visión trágica de la historia se encuentra en la fe cristiana: al igual que el marxismo y a diferencia del liberalismo, ambas asumen la depravación y la perversidad humana, y ambas tienen esperanza en la posibilidad de subsanar tal cosa. Las dos creencias tienen una visión sombría de la especie humana, que es condición para la esperanza. Eagleton establece que esta mirada trágica no es pesimista, ya que su interpretación de la trágico se encuentra íntimamente ligada a la esperanza. De igual modo, para nuestro autor, tanto el marxismo como la fe cristiana comparten no solo el diagnóstico (el carácter atroz de la historia), sino también, dado lo anterior, la convicción de que el remedio debe ser radical (no reformista), ambos elementos claves de la tragedia.

La necesaria radicalidad del remedio requiere la autorrenuncia: esa es la premisa con la que inicia el ulterior apartado (4. "El sacrificio como signo de reconstrucción radical"). Allí expusimos el modo en que Eagleton atiende a la dinámica autonegación-reconstrucción que presenta el sacrificio en el cristianismo, indicando que la modernidad ve en aquel solo el aspecto de autonegación. Para nuestro autor el sacrificio tiene la estructura de la tragedia porque: a) es autonegación (pérdida), pero también florecimiento, nueva vida (creación); b) resulta necesario por la calamidad de la situación, no sería posible la transfiguración de lo existente sin sacrificio. De lo dicho se desprende que para Eagleton el sufrimiento es malo, e interpreta que también es así para la fe cristiana. Entiende que ello se advierte en los Evangelios, particularmente en el episodio de Getsemaní. El sacrificio no es la imagen de la buena vida, sino de lo que se necesita para lograrla, y es también testimonio de la posibilidad de la transfiguración y medio esencial para su logro práctico. Nuestro autor afirma que esta valoración del sacrificio (desgraciado y necesario) es común al cristianismo y al marxismo, porque ambos ven que la historia es catástrofe, por tanto, que se requiere una transformación radical, y que el preludio para ello es el sacrificio. Finalmente, el sacrificio anuncia la transfiguración, pero solo asumiendo el fracaso puede fructificar lo nuevo: por eso es un acto supremo de fe.

El último apartado aborda la fe en la trasfiguración (5. "Esperanza"), y se divide en dos secciones. En la primera de ellas (5.1. "Demarcación frente al optimismo progresista"), Eagleton distingue la esperanza del optimismo: el optimismo es fatalista (todo tiende a ir mejor) y por ello no propone ninguna transformación radical. Se realiza una disquisición en torno a la discontinuidad de la idea de Progreso con la escatología cristiana, en tanto la primera postula un mejoramiento continuo, el cual es inmanente. Eagleton comprende que la escatología cristiana, al igual que el marxismo, rechaza la mirada cándida de la historia 
como perfeccionamiento ininterrumpido, y postula que ambos entienden la transfiguración como algo que es tanto trascendente como inmanente: ver solo irrupción nos conduciría al apocalipticismo, y ver solo inmanencia nos lleva al historicismo. En el presente (para el marxismo y para el catolicismo) debe poder vislumbrase un futuro, aunque la continuidad entre historia y futuro no es en forma de teleología historicista, sino de lo que se trata es de recobrar la tradición, de recobrar las luchas del pasado redimiéndolas (buscando obtener valor del sufrimiento).

La última sección (5.2. "Acerca de la esperanza") desarrolla el modo en que Eagleton entiende la esperanza. Se trata, nos dice, de una forma de deseo que incluye la expectativa, que se orienta hacia lo posible mas no cuenta con certeza de alcanzar su propósito, que se basa en razones (aunque no convicciones), y que conlleva un impulso de realización, en tanto virtud que se manifiesta prácticamente. La esperanza no es de por sí benigna, pero en tanto virtud puede cultivarse, orientándose hacia lo bueno (mediante la intervención de una racionalidad valorativa). Empero cierto contenido indeterminado es consustancial a la esperanza: es propio de la esperanza cierta indeterminación en lo que se propone realizar así como la incertidumbre en cuanto a su realización. Finalmente, la esperanza es parcialmente performativa: además de anticipar el futuro puede contribuir a realizarlo (lo cual no quiere decir que el futuro anhelado se realizará simplemente porque nosotros tengamos esperanza).

Entre estas reconsideraciones de Eagleton respecto a la historia, y las versiones predominantes en el marxismo del "corto siglo XX", media un cambio de época. La historia de la lucha por el socialismo ha estado plagada de derrotas y sacrificios; sin embargo, dotado de una visión historicista teleológica, el marxismo "«metabolizaba» las derrotas, eliminando o disminuyendo su carácter doloroso y a veces devastador" (Traverso, 2018, p. 108). En este sentido, esta dialéctica de la derrota adoptaba "la forma de una teodicea secular: el bien podía nacer del mal, y la victoria final era la resultante de un encadenamiento de derrotas" (Traverso, 2018, p. 108). Así, el sacrificio resultaba necesario, porque era inevitable dada la catástrofe de la historia, pero sobre todo porque necesariamente conducía al telos anhelado.

Desde esta matriz de ideas, el Che Guevara anticipaba su martirio: "Todos y cada uno de nosotros paga puntualmente su cuota de sacrificio, conscientes de recibir el premio en la satisfacción del deber cumplido, conscientes de avanzar con todos hacia el hombre nuevo que se vislumbra en el horizonte" (2004, p. 424). De modo que los sacrificios y derrotas se inscribían en el relato de la ineluctable victoria, eran batallas perdidas en una guerra de triunfo seguro. Una "concepción obstétrica" de la revolución se hallaba fuertemente enraizada en el imaginario de la época; el mismo Guevara lo visualizaba de este modo: 
las fuerzas reaccionarias de la vieja sociedad [...] se resisten a dejar nacer la sociedad nueva, que es engendrada por las contradicciones que lleva en su seno la vieja sociedad. La revolución es en la historia como el médico que asiste al nacimiento de una nueva vida. No usa sin necesidad los aparatos de fuerza, pero los usa sin vacilaciones cada vez que sea necesario para ayudar al parto. Parto que trae a las masas esclavizadas y explotadas la esperanza de una vida mejor (2004, p. 91).

Como fue mencionado, entre aquel momento de la historia y la actualidad media un cambio de época, signado por una serie de sucesos (entre los cuales se cuenta el asesinato del mismo Guevara) que configuraron el hundimiento del proyecto comunista. El triunfo del neoliberalismo conllevó (entre tantas otras cosas) una modificación de la percepción del pasado y una nueva imaginación histórica: "La expectativa [futuro] ha desaparecido; la experiencia [pasado], por su parte, ha adoptado la forma de un campo de ruinas" (Traverso, 2018, p. 33). Domina un "presentismo" (Hartog, 2007) que disuelve en sí mismo tanto al pasado como el futuro.

Esta ruptura de la dialéctica pasado-futuro, propia de nuestro tiempo, destierra la certeza teleológica del imaginario socialista. Si aquella inscribía las derrotas acaecidas en una dinámica anticipatoria, fortaleciendo así el proyecto de emancipación, al romperse la dialéctica pasado-futuro solo se ve en el pasado una montaña de ruinas, y en el futuro nada diferente al presente. La mirada trágica de la historia le permite a Eagleton superar este presentismo, sin recaer en la teleología. Así, por un lado, su perspectiva del pasado afronta la catástrofe de la historia, y "[p]ercibe las tragedias y las batallas perdidas del pasado como un peso y una deuda, que también son una promesa de redención” (Traverso, 2018, p. 20). Esa es la vinculación con el futuro, no ya en forma de bella teleología, sino de una esperanza que solo puede surgir de asumir el carácter atroz de la historia, de asumir la derrota como algo definitivo, total. De ahí que nuestro autor entienda el sacrificio no como una autonegación vivida con los ojos puestos en la recompensa: el sacrificio es tal si es asumido como un sacrificio por nada, y solo así podría, finalmente, ser por algo. El sacrificio debe ser asumido como fracaso; solo así puede surgir la esperanza. Su imagen de Él no se asocia al Christus Vincit, sino a la de Lamentación sobre el Cristo muerto.

Dada su comprensión de que la esperanza solo puede surgir de la asunción de la derrota total, Eagleton orienta su reflexión acerca de la esperanza hacia motivos teológicos, y no opta, por caso, por buscar un socio (más "secular") en la utopía. De hecho, en una primera mirada, la comprensión de Eagleton de la esperanza parece compartir motivos con lo que diversos investigadores han denominado "lo utópico operante en la historia" (Aínsa, 1991, Cerutti Guldberg, 2010): estructura dual compuesta de crítica a lo existente y expectativa en su superación (razonable y posible), que moviliza a la acción, y que presenta incertidumbre acerca de su realización, así como cierta indeterminación respecto a su contenido. Empero lo utópico operante en la historia se concentra en el porvenir de la sociedad buena, y en Eagleton la esperanza de un mundo nuevo está indisolublemente 
ligada a la imaginación del desastre que lo antecede. Y esta mirada trágica encuentra mejores argumentos en la teología cristiana (tal como la entiende Eagleton).

\section{Referencias bibliográficas}

Aínsa, F. (1991). Necesidad de la utopía. Montevideo: Nordan-Tupac.

Bartra, A. (2016). Hacia un marxismo mundano. La clave está en los bordes. México: UAMItaca.

Benjamin, W. (2008). Tesis sobre la historia y otros fragmentos. México: ITACA. Traducción:

Bolívar Echeverría.

Bloch, E. (2007). El principio esperanza. Madrid: Trotta. Traducción: Felipe González Vicén.

Blumenberg, H. (2008). La legitimación de la Edad Moderna. Valencia: Pre-Textos. Traducción: Pedro Madrigal.

Callinicos, A. (2011). Contra el posmodernismo. Buenos Aires: Ediciones RyR. Traducción: Magdalena Holguín.

Cerutti Guldberg, H. (2010). Utopía es compromiso y tarea responsable (Ensayos de Utopía V). Monterrey: CECyTE.

Cohen, G. A. (2001). Si eres igualitarista ¿cómo es que eres tan rico?. Barcelona: Paidós. Traducción: Luis Arenas Llopis y Oscar Arenas Llopis.

Eagleton, T. (2004). El portero. Memorias. Barcelona: Debate. Traducción: Luis María Brox. Eagleton, T. (2008). Terror santo. Buenos Aires: Debate. Traducción: Ricardo García Pérez. Eagleton, T. (2010). Los extranjeros. Por una ética de la solidaridad. Madrid: Paidós. Traducción: Antonio Francisco Rodríguez Esteban.

Eagleton, T. (2012a). Razón, fe y revolución. Reflexiones en torno al debate sobre Dios. Barcelona: Paidós. Traducción: Albino Santos Mosquera.

Eagleton, T. (2012b). Terry Eagleton presenta a Jesucristo. Madrid: Akal. Traducción: Alfredo Brotons Muñoz.

Eagleton, T. (2012c). Figuras del disenso. Ensayos críticos sobre Fish, Spivak, Žižek y otros autores. Buenos Aires: Prometeo. Traducción: Luisa Fernanda Lassaque.

Eagleton, T. (2012d). Walter Benjamin o hacia una crítica revolucionaria. Madrid: Cátedra. Traducción: Julia García Lenberg.

Eagleton, T. (2015). Sobre el mal. México: Teotihuacán. Traducción: Albino Santos Mosquera.

Eagleton, T. (2016). Esperanza sin optimismo. México: Taurus. Traducción: Belén Urrutia.

Eagleton, T. (2017a). El sentido de la vida. Barcelona: Paidós. Traducción: Albino Santos Mosquera.

Eagleton, T. (2017b). La cultura y la muerte de Dios. Buenos Aires: Paidós. Traducción: Fermín Rodríguez. 
Eagleton, T. (2017c). Santos y eruditos. Buenos Aires: El cuenco de plata. Traducción: Teresa Arijón.

Eagleton, T. (2018a). Por qué Marx tenía razón. México: Ariel. Traducción: Albino Santos Mosquera.

Eagleton, T. (2018b). Radical Sacrifice. Padstow: Yale University Press.

Echavarría, A. (2009). Teodicea. En Diccionario de Filosofía (pp. 1083-1087). Pamplona: EUNSA.

Goldmann, L. (1986). El hombre y lo absoluto. El dios oculto. Barcelona: Planeta-Agostini. Traducción Juan Ramón Capella.

Guevara, E. (2004). Obras Escogidas. Santiago de Chile: Resma.

Hartog, F. (2007). Los regímenes de historicidad. Presentismo y experiencias del tiempo. México: Universidad Iberoamericana. Traducción: Norma Durán.

Liebniz, G. W. (2013). Ensayos de Teodicea. Sobre la bondad de Dios, la libertad del hombre y el origen del mal. Salamanca: Sígueme. Traducción: Miguel García-Baró y Mercedes Huarte.

Löwith, K. (2007). Historia del mundo y salvación. Los presupuestos teológicos de la filosofía de la historia. Buenos Aires: Katz. Traducción: Norberto Espinosa.

Marx, K. y Engels, F. (1974). La ideología alemana. Barcelona: Grijalbo. Traducción: Wenceslao Roces.

Marx, K. (2008). Contribución a la crítica de la economía política. México: Siglo XXI. Traducción: León Mames.

Petruccelli, A. (2016). Ciencia y utopía. En Marx y en la tradición marxista. Buenos Aires: Herramienta-El Colectivo.

Sánchez Vázquez, A. (1987). Ética. México: Grijalbo.

Steiner, G. (2018). La muerte de la tragedia. México: Fondo de Cultura Económica. Traducción: Enrique Luis Revol.

Traverso, E. (2012). Melancolía de izquierda. Marxismo, historia y memoria. Buenos Aires: Fondo de Cultura Económica. Traducción: Horacio Pons.

Trotsky, L. (2014). Literatura y revolución. Buenos Aires: RyR. Traducción: Alejandro Ariel González. 